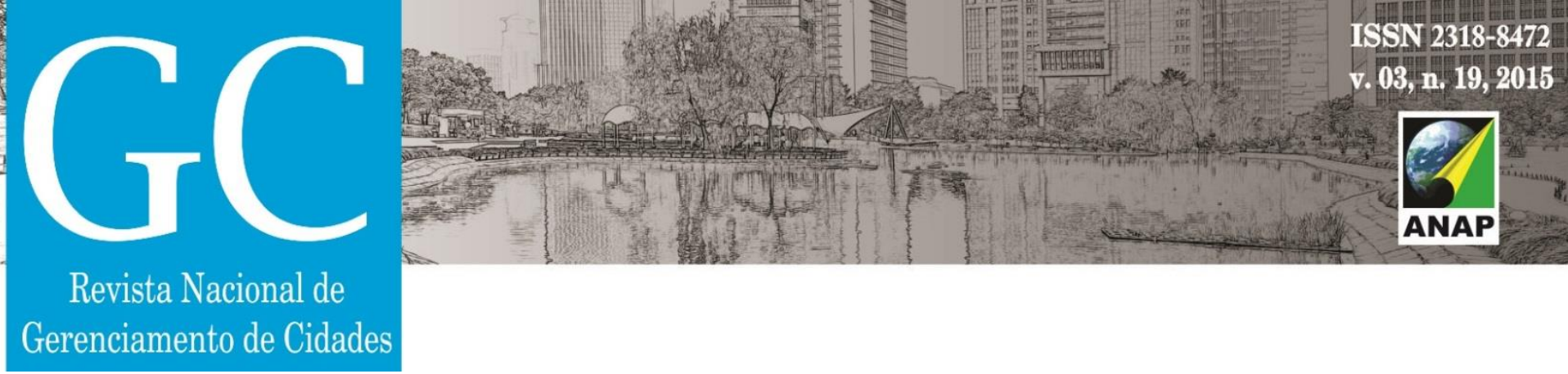

\title{
AS INFLUENCIAS DOS USOS DAS TERRAS NA BACIA HIDROGRÁFICA DO CÓRREGO BREJO ALEGRE DE ARAGUARI (MG) SOBRE A QUALIDADE DAS ÁGUAS.
}

Crislane Calixto Pereira ${ }^{1}$

João Donizete Lima²

\begin{abstract}
RESUMO
Os diversos usos das terras, principalmente utilizado de forma errônea desencadeou na Bacia Hidrográfica do Córrego Brejo Alegre a degradação e desequilíbrios principalmente em seu recurso hídrico, o córrego Brejo Alegre, e seus afluente córrego Dâmasus e Desbarrancado. O presente estudo, perpassou por o desenvolvimento metodológico dividido em referencial teórico, pesquisa de laboratório e trabalho a campo. Esse desenvolvimento metodológico foi essencial para alcançar o objetivo do estudo que é compreender o uso do solo e sua influencia sobre a qualidade da água. No quesito qualidade da água foram analisado os parâmetros de $\mathrm{Ph}$, Turbidez e Oxigênio Dissolvido, no entanto os resultados não foram satisfatórios, já que alguns pontos escolhidos, os dados não representaram a realidade local.
\end{abstract}

PALAVRAS-CHAVE: Usos das terras, Bacia Hidrográfica do Córrego Brejo Alegre, Qualidade da água.

\section{THE INFLUENCES OF USES OF LAND IN THE BASIN CÓRREGO BREJO ALEGRE DE ARAGUARI (MG) ON THE QUALITY OF THE WATERS.}

\footnotetext{
${ }^{1}$ Geógrafa, mestranda da Universidade Federal de Goiás - Regional Catalão. crislanecpereira@yahoo.com.br.

${ }^{2}$ Geógrafo, Professor da Universidade Federal de Goiás - Regional Catalão. donizeteufg@gmail.com.
} 


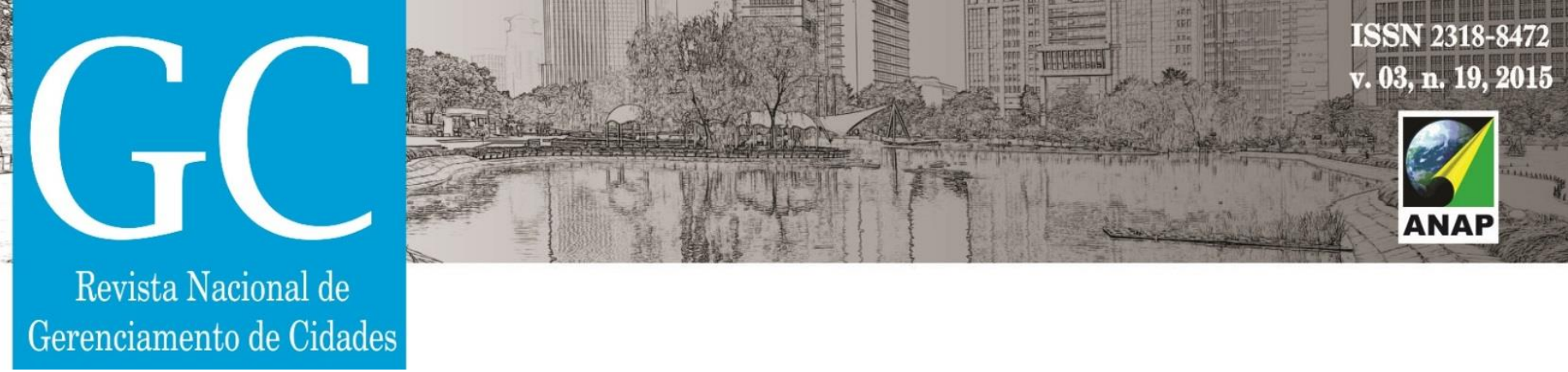

\begin{abstract}
The different land uses, mainly used wrongly triggered in Basin Swamp Stream Alegre degradation and imbalances mainly on their water resources, stream Brejo Alegre, and its tributary stream Damasus and Desbarrancado. This study, pervaded by the methodological development divided into theoretical, laboratory research and field work. This methodological development was essential to achieve the goal of the study is to understand the land use and its influence on water quality. On the issue of water quality were analyzed Ph parameters, turbidity and dissolved oxygen, however the results were not satisfactory, as some selected points, the data did not represent the local reality.
\end{abstract}

KEYWORDS: Uses of land, Watershed Stream Brejo Alegre, Water quality.

\title{
LAS INFLUENCIAS DE USOS DE LA TIERRA EN LA CUENCA CÓRREGO BREJO ALEGRE DE ARAGUARI (MG) SOBRE LA CALIDAD DE LAS AGUAS.
}

\section{RESUMEN}

Los diferentes usos de la tierra, principalmente utilizado erróneamente desencadenado en la Cuenca del pantano degradación Corriente Alegre y desequilibrios principalmente en sus recursos hídricos, Tráfico Brejo Alegre, y su afluente arroyo Dámaso y Desbarrancado. Este estudio, impregnado por el desarrollo metodológico divide en teórica, la investigación de laboratorio y trabajo de campo. Este desarrollo metodológico era esencial para lograr el objetivo del estudio es entender el uso de la tierra y su influencia en la calidad del agua. Sobre la cuestión de la calidad del agua se analizaron los parámetros de $\mathrm{pH}$, turbidez y oxígeno disuelto, sin embargo los resultados no fueron satisfactorios, ya que algunos puntos seleccionados, los datos no representan la realidad local.

PALABRAS CLAVE: Usos de la tierra, de la Cuenca Riachuelo Brejo Alegre, la calidad del agua.

\section{Introdução}

A B.H. do Córrego Brejo Alegre, por ser uma bacia urbana, em que $80 \%$ de seu sistema hídrico se concentra dentro da cidade de Araguari (MG), absorve todos os danos causados pela ocupação humana. Os diversos usos das terras, principalmente utilizado de forma errônea desencadeou na referida Bacia a 


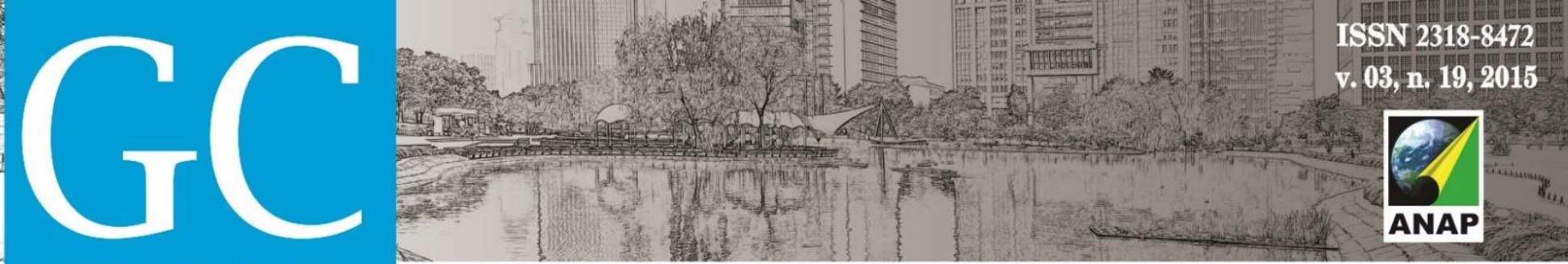

Revista Nacional de

Gerenciamento de Cidades

degradação e desequilíbrios principalmente em seu recurso hídrico, o córrego Brejo Alegre, e seus afluente córrego Dâmasus e Desbarrancado.

Nesse sentido, o objetivo do estudo é compreender o uso do solo e sua influencia sobre a qualidade da água. Para alcançar o objetivo a metodologia perpassa por três etapas, sendo a primeira etapa diz respeito ao referencial teórico, a segunda, se refere a pesquisa de laboratório, destinado à elaboração do mapa de localização e de uso da terra da década de 2014, no Laboratório de Geoprocessamento da U.A.E.IGEO/RC/UFG. E a terceira, sendo o trabalho de campo, para a averiguação da influencia do uso das terras sobre a qualidade da água, observando os principais pontos que são visíveis essas influencias desses usos das terras e por fim para coleta de dados físicos referentes a qualidade de água.

\section{Metodologia}

Dentre as etapas da metodologia foi essencial o referencial teórico, e contase com obras de: Santos (2005), Cunha e Guerra (2004), AB' Sáber (2005), Bastos e Freitas (2004), Bertoni (1968) e (1990), Casseti (1991), Farage (2009), Melo (2006), Naves e Rios (1988), Ross e Prette (1998), Santos (2004), Tundisi e Matsumura - Tundisi (2011), e outros referenciais como: Frota (2006), Parron; Muniz; Pereira (2011), CETESB (2009). Gonçalves e Guerra (2005, p. 190) Ab'Sáber (2005) , Araújo (2010), Gonçalves (1984), Bastos e Freitas (2004).

$\mathrm{Na}$ segunda etapa da metodologia a pesquisa de laboratório, que ocorreu a elaboração dos mapas, para tal, foi necessária a extração de bases de dados cartográficos, como imagens satélites, carta topográfica de Uberlândia (MG) e outros, como vetores do município dispostos no Instituto Brasileiro de Geografia e Estatística (IBGE). A partir desses dados cartográficos e imagens foi possível reconhecer e delimitar a área para produzir mapas de uso da terra da década $2014 \mathrm{e}$ mapa de localização. 


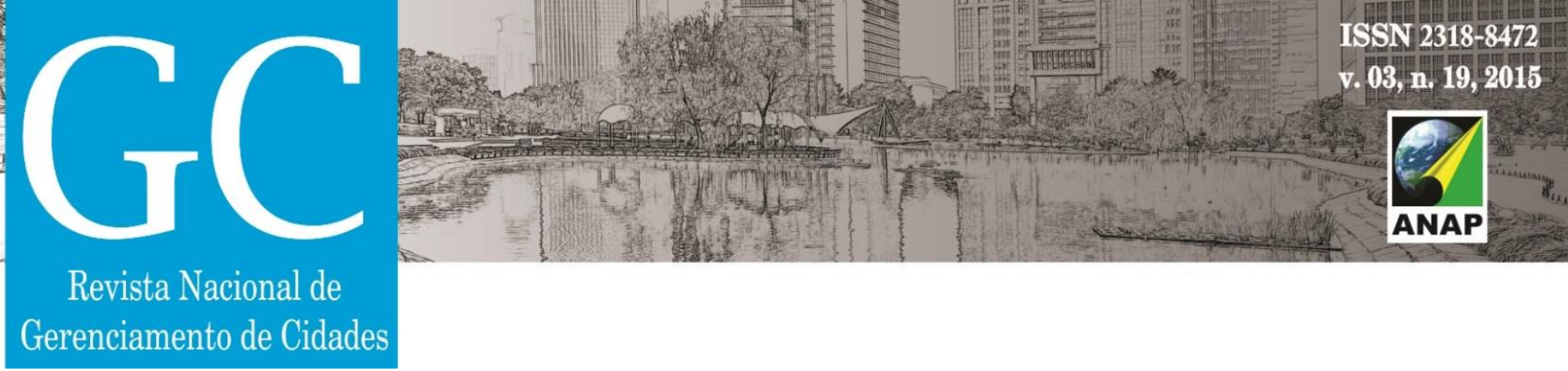

estado de Goiás, fazendo divisa com os municípios de Catalão, Anhanguera, Cumarí e Corumbaíba.

Os acessos ao município de Araguari são possibilitados por meio da Rodovia Federal BR-050, que interliga Uberlândia e percorre os estados de Minas Gerais e São Paulo, ao Sul, e o estado de Goiás e Distrito Federal, ao Norte. As rodovias estaduais MG-028 ligam Araguari a Indianópolis (MG), a rodovia MG-223 interliga Araguari a Tupaciguara (MG) sendo a sequência da MG 223 a rodovia MG413, que liga Araguari a Caldas Novas (GO).

O município de Araguari possui um extenso sistema hídrico composto principalmente pelos córregos: Araras, Desamparo, Verde, Macaúbas, do Retiro, Bacuri, Santa Maria, Ressaca, Brejo Alegre, que são tributários, do rio Araguari, ribeirão Jordão ou diretamente do rio Paranaíba.

Dentre esses córregos, ribeirões e rios, vale destacar o córrego Brejo Alegre como objeto de estudo dessa pesquisa, sendo este tributário do ribeirão Jordão, que desagua no rio Paranaíba. O Córrego Brejo Alegre tem como principais tributários o córrego Dâmasus e o córrego Desbarrancado, que formam a Bacia do Córrego Brejo Alegre, localizada entre as coordenadas geográficas $18^{\circ} 36^{\prime}$ e $18^{\circ} 40^{\prime}$ de latitude Sul e 48¹2' e 48 $8^{\prime}$ de longitude Oeste, como mostra a figura 01. 


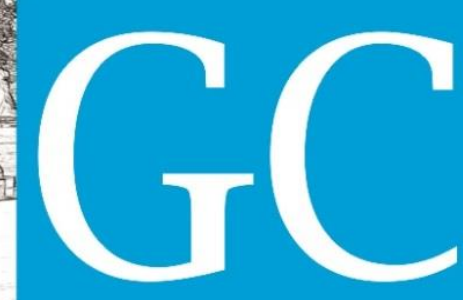

Revista Nacional de

Gerenciamento de Cidades

Figura 01 - Localização da Bacia Hidrográfica do Córrego Brejo Alegre

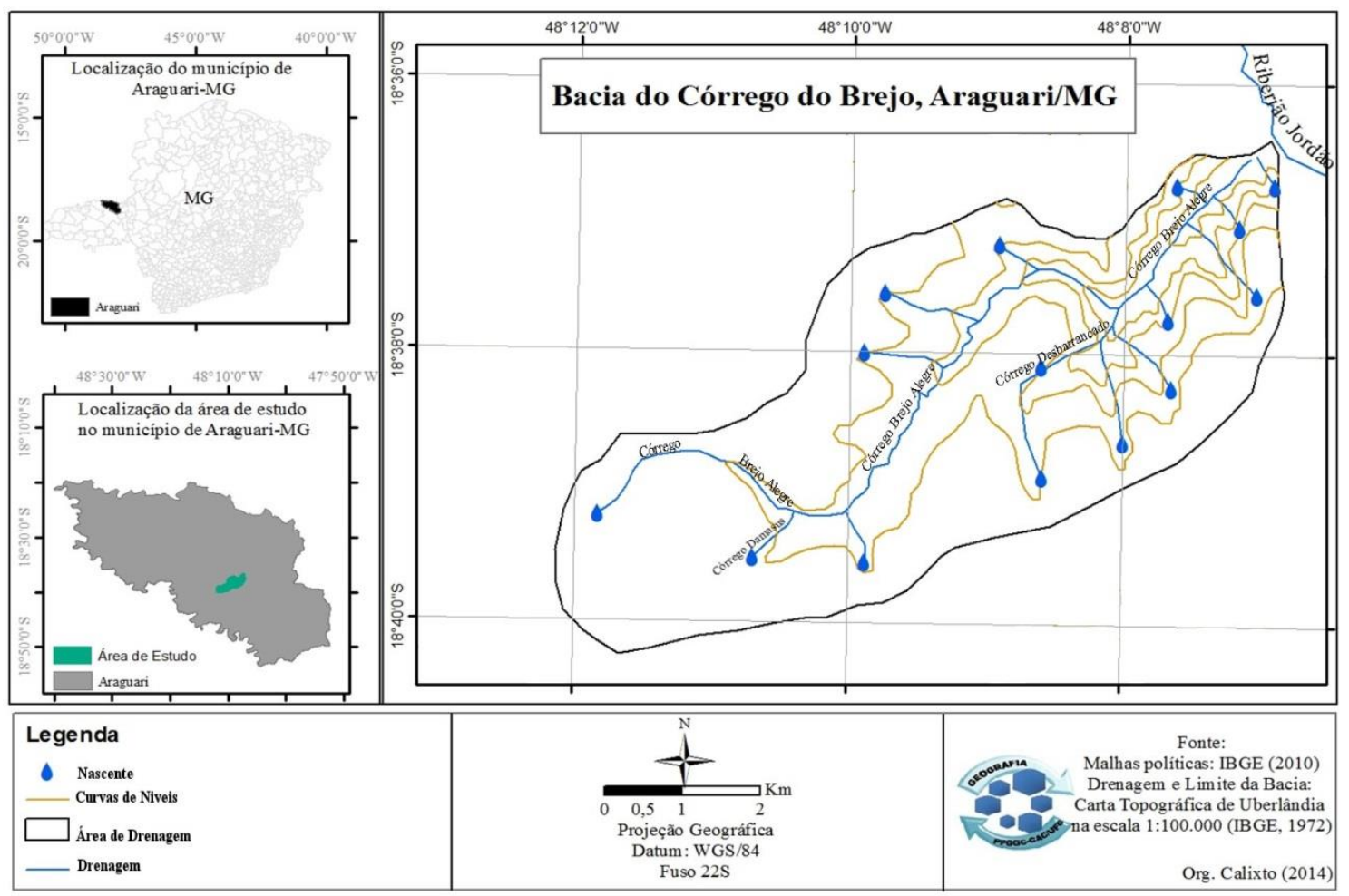

Organização: CALIXTO, Crislane [Pereira]

\section{Desequilíbrios proporcionados ao meio ambiente por meio das ações antrópicas}

Atualmente, o ambiente sofre alterações por meio de ações antrópicas. Entre as principais modificações, tem-se: áreas urbanizadas, concentração de edificações, áreas asfaltadas e impermeabilizadas, desmatamento, diminuição nas precipitações ou aumento de chuvas torrenciais, uso irracional do solo, exposição do solo a intempéries climáticas, perca de partículas, nutrientes e minerais do solo, esgotamento do solo, assoreamento, processos erosivos, redução das camadas superficiais do solo, modificação do relevo e da paisagem. Sobre isso, Bertoni (1960, p.5) explica que: 


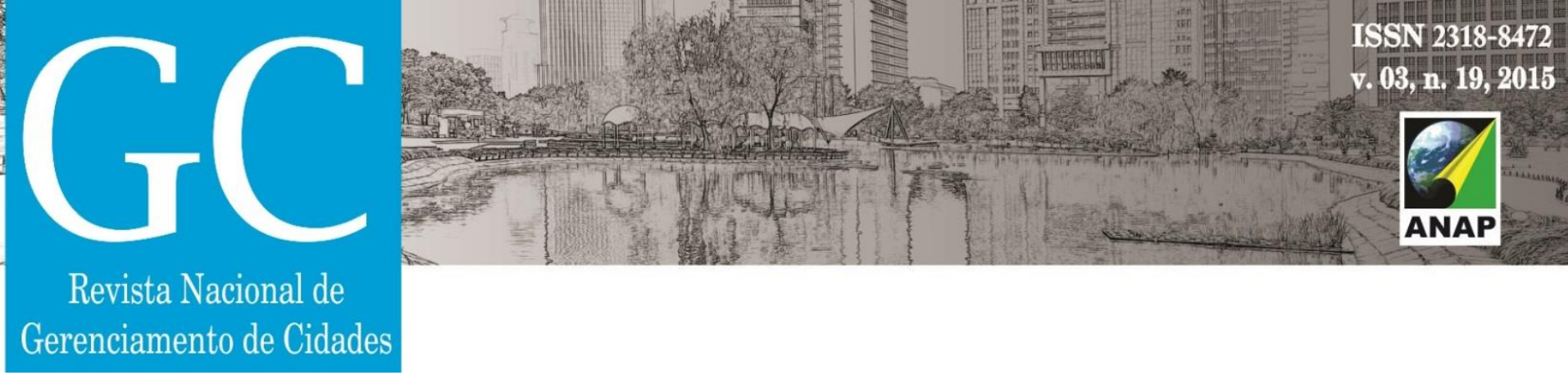

No que se refere aos impactos ocorridos ao ambiente, Bastos e Freitas (2004, p.19) expõe que [...] A ocupação do solo deforma inconsequente e, acelerada no último século, sem a implantação de uma infraestrutura adequada contribui bastante para os vários danos ambientais atualmente observados. Gonçalves e Guerra (2005, p. 190) complementam que "as cidades constituem hoje o maior exemplo de degradação ambiental, colocando em risco a segurança e a qualidade de vida de sua população, constituindo um palco de embates ecológicos”.

Considerando as cidades o propulsor da degradação ambiental, e nesta gera impactos pontuais, que interfere em todo um sistema natural interligado e proporciona desiquilíbrios, pode-se destacar os impactos ocorridos nos recursos hídricos, que atualmente, mesmo indicativos de escassez, suporta uma sobrecarga aos diversos tipos de uso, em principal, para o consumo humano, para atendimento das industriais e para agricultura, ainda está sendo desperdiçada, pois córregos, ribeirões e rios, principalmente os urbanos estão sendo poluídos, o que altera a qualidade da água e inviabiliza a água para o consumo, para os diversos tipos de uso, e ainda causa danos a vida aquática e saúde da população.

Na Bacia Hidrográfica do Córrego Brejo Alegre a contaminação da água é visivelmente perceptível, além de apresentar um elevado grau de degradação, o que ocorreu por diversos fatores, como: retirada da vegetação nativa, ocupação humana inadequada e desordenada, alteração através de aterramento, canalização, impermeabilização do solo, despejo de efluentes industriais e domésticos in natura sem nenhuma forma de tratamento, e descarte irregular de resíduos sólidos.

O Córrego Brejo Alegre, canal nasce no perímetro urbano de Araguari (MG), mais especificamente na área central da cidade, porém, está canalizado nessa região e, por isso, é imperceptível, e muitas vezes ignorado pela população citadina. Além disso, ele percorre também a área rural, sendo visível a degradação do ambiente e principalmente da água.

Para melhor compreender a atual conjuntura da B.H do Córrego Brejo Alegre foi analisado o mapa do uso da Terra de 2014, na figura 02, nota-se a concentração 


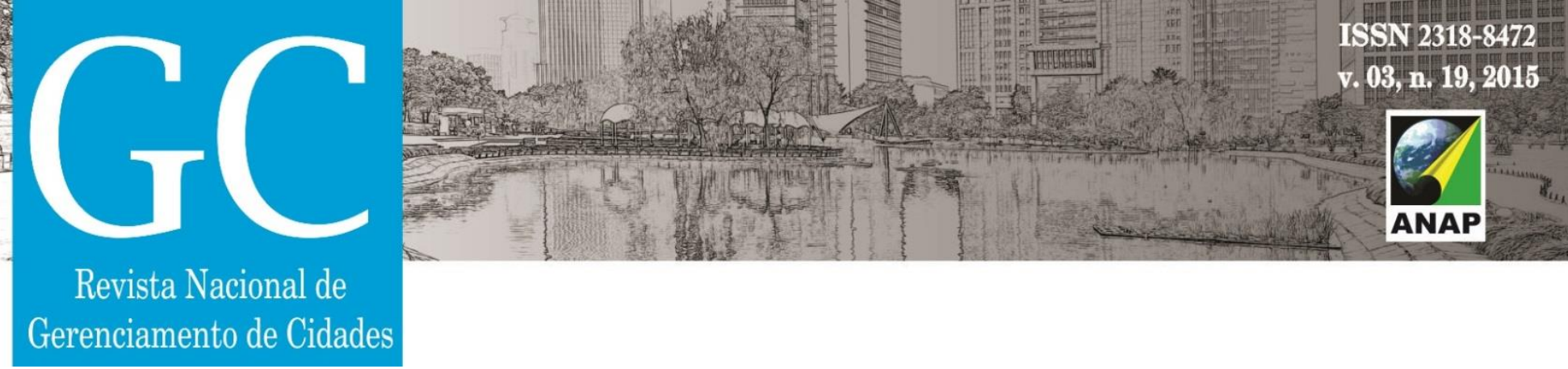

do sítio urbano, na área da referida bacia, e nas margens do córrego Brejo a concentração de indústrias (Distrito Industrial), e nas proximidades do córrego o aterro sanitário do município. Todos os efluentes domésticos dessas indústrias e edificações são direcionados ao córrego sem o devido tratamento. Ainda na figura 02, nota-se também as áreas destinadas a agricultura, terras utilizadas para a lavouras de café, eucalipto, mas em campo observa-se o predomínio das plantações de frutos e leguminosas, e em áreas industriais.

Figura 2 - Uso da terra e cobertura vegetal da década de 2014 da Bacia Hidrográfica do Córrego Brejo Alegre

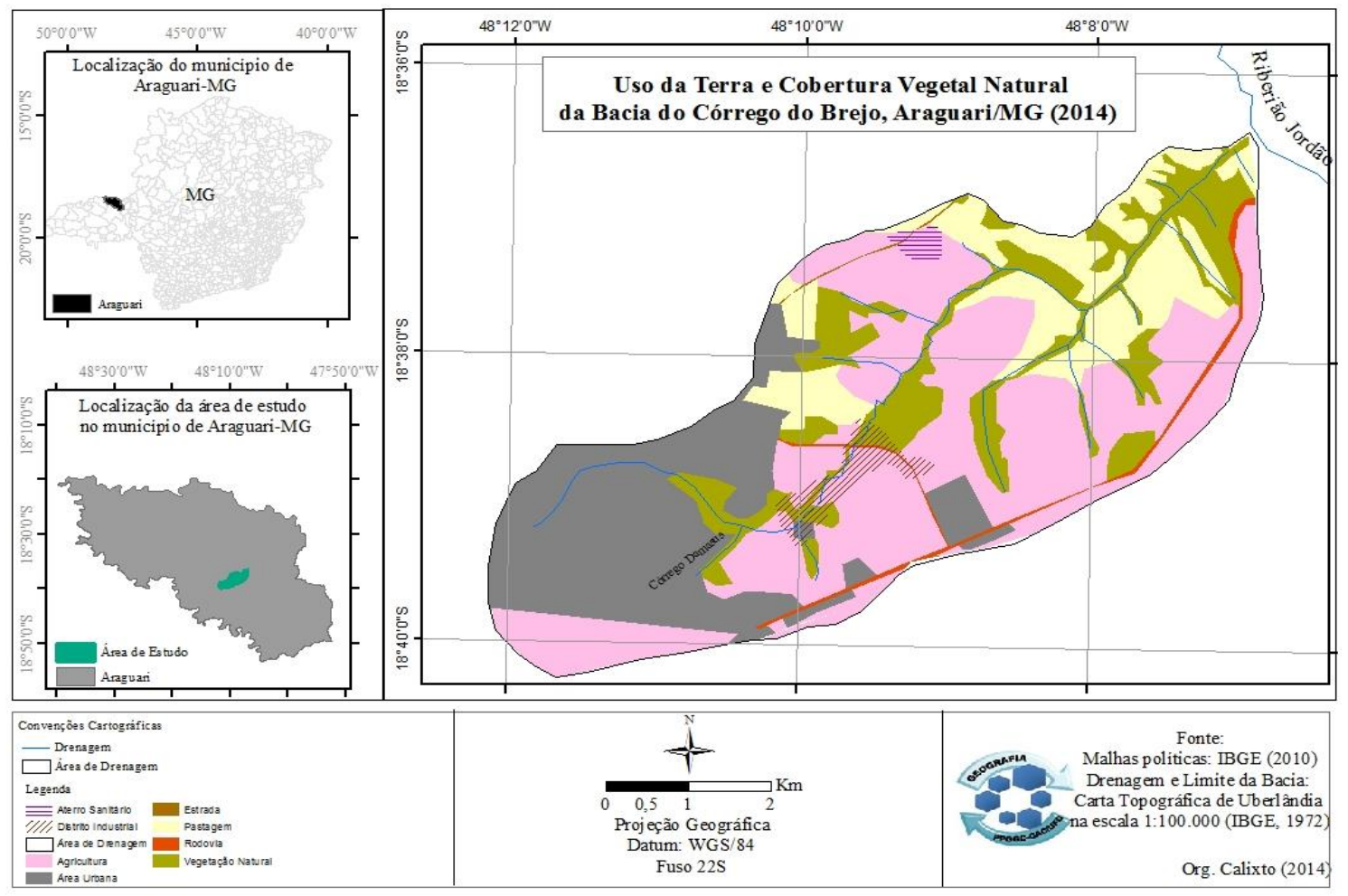

Organização: CALIXTO, Crislane [Pereira]

Desse modo, na área de 3429,332hectares da B.H do córrego Brejo Alegre, a tabela 01, mostra como se estabeleceu a distribuição de uso das terras em alqueires e porcentagem. Em destaque o predominio de áreas de agricultura, como 


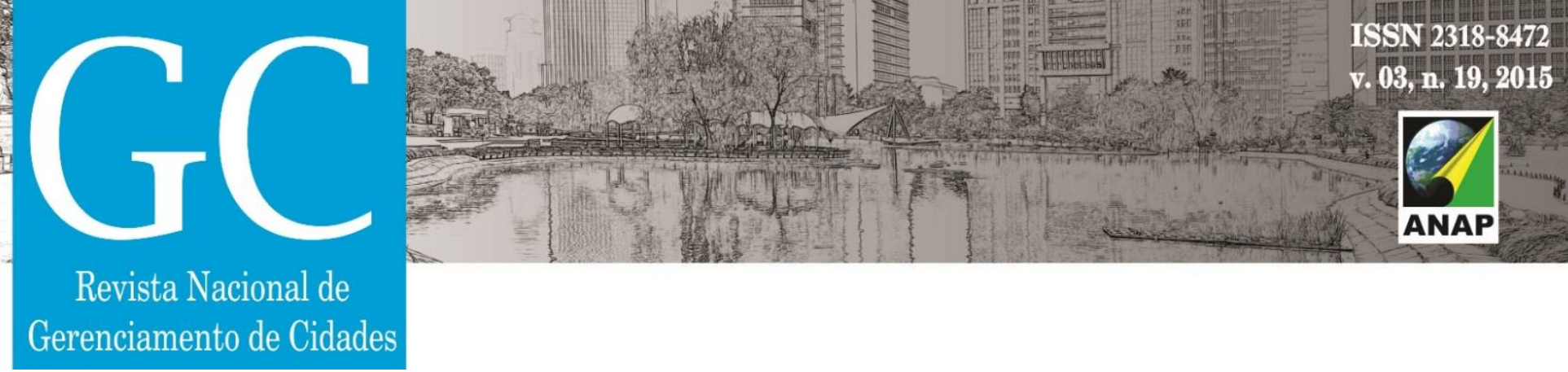

mostra a tabela representando $41,51 \%$ de áreas da B.H. do córrego Brejo Alegre; as áreas urbanas a logo em seguida com 25,5 \%, a vegetação nativa representando $16,39 \%$, e as áreas de pastagens representando15,10\%.

Tabela 01: Uso das terras na Bacia Hidrográfica do Córrego Brejo Alegre

\begin{tabular}{c|c|c}
\hline Classe de uso de área & Área em alqueires & Área em \% \\
Área urbana & 874,5017 & 25,5 \\
Agricultura & 1423,375 & 41,51 \\
Estrada & 4,3164 & 0,13 \\
Pastagem & 517,7025 & 15,1 \\
Rodovia & 47,227 & 1,38 \\
Vegetação natural & 562,2086 & 16,39 \\
Área total & 3429,332 & $100 \%$ \\
\hline Fonte: Trabalho a campo, 2014, Organização: CALIXTO, Crislane [Pereira].
\end{tabular}

\section{Análise dos Parâmetros de qualidade da água: $\mathrm{Ph}$, Turbidez e Oxigênio Dissolvido}

Constatado os diferentes usos das terras e o predomínio de áreas destinadas a agricultura e urbano, a averiguação dessas influencia sobre a qualidade da água ocorreu por meio de analises da água in loco, através da sonda multiparametro Horiba U-10, do qual forneceu dados da turbidez, do PH (Potencial Hidrogeoniônico) e Oxigênio Dissolvido, visto que esses dados, demonstram as alterações nas características físicas da água, e interfere no ambiente aquático e na qualidade da água.

Para a averiguação dos qualidade da água foram definidos 6 pontos a serem analisados. O primeiro ponto de coleta, localizado na foz do córrego Brejo Alegre,

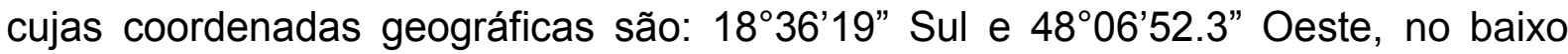
curso do córrego Brejo Alegre, a água é receptora de todas as atividades urbanas, industriais e de atividades agropecuárias.

Com as coordenadas geográficas de latitude 18 $18^{\circ} 37^{\prime} 31^{\prime \prime}$ Sul e longitude $048^{\circ} 06^{\prime} 46.2^{\prime \prime}$ Oeste, o segundo ponto de coleta se localiza nas proximidades do 


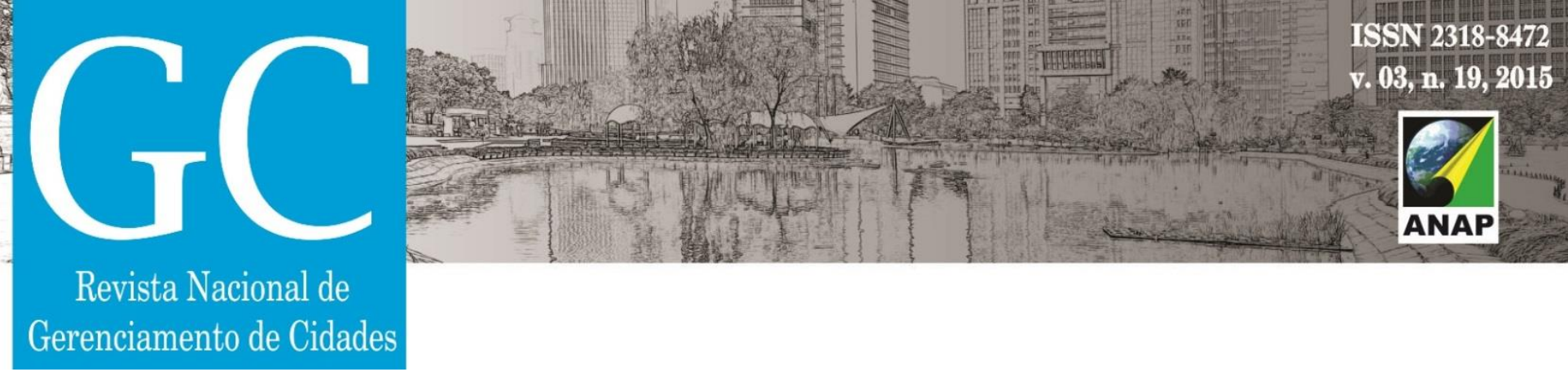

BRASIL. Resolução Conama $n^{\circ}$ 357, de 17 de março de 2005. Dispõe sobre a classificação dos corpos de água. Resoluções do Conama: Resoluções vigentes publicadas entre setembro de 1984 e janeiro de 2012. Brasília: MMA, 2012. 376-402 p.

BRASIL.. Lei Orgânica do Município, Araguari - MG de 21 de Abril de 1990. f 68.Disponivel em

CASSETI, Valter Ambiente e apropriação do relevo São Paulo : Contexto, 1991. 147 p.

CETESB - Companhia Ambiental do Estado de São Paulo. Qualidade das águas interiores no estado de São Paulo (Série Relatórios) - Apêndice A, SIGNIFICADO AMBIENTAL E SANITÁRIO DAS VARIÁVEIS DE QUALIDADE DAS ÁGUAS E DOS SEDIMENTOS E METODOLOGIAS ANALÍTICAS DE AMOSTRAGEM - 2009, 43p.

CUNHA, Sandra Bapthista da. Canais Fluviais e a questão ambiental In: CUNHA, Sandra Bapthista da; GUERRA, Antônio José Teixeira (org.) A questão ambiental: diferentes abordagens. Rio de Janeiro: Bertrand Brasil, 2007. p. 219 -238.

CUNHA, Sandra Bapthista da. Canais Fluviais e a questão ambiental In: CUNHA, Sandra Bapthista da; GUERRA, Antônio José Teixeira (org.) A questão ambiental: diferentes abordagens. Rio de Janeiro: Bertrand Brasil, 2007. p. 219 -238.

DREW, David. Processos interativos homem-meio ambiente. Rio de Janeiro - RJ, Bertrand Brasil, 2002, $224 \mathrm{p}$.

FROTA; Patrícia Vasconcelos. Propostas para gestão integrada de recursos hídricos na Bacia Hidrográfica do Rio Jardim - DF 2006, 166 f. Dissertação (Mestrado em Geografia), Universidade de Brasília (UNB), Brasília. Disponível em

FUNASA, Brasil. Ministério da Saúde. Fundação Nacional de Saúde. Manual de controle da qualidade da água para técnicos que trabalham em ETAS-2014.f 112- Brasília: Funasa. 1. Controle da qualidade da água I. 2. Aspectos Técnicos. Disponível em:<http://www.funasa.gov.br/site/wpcontent/files_mf/manualcont_quali_agua_tecnicos_trab_emetas. pdf $>$ Acesso em: 20 de janeiro de 2015

TUNDISE; José Galizia, MATSUMURA-TUNDISE; Tanako. Recursos hídricos no século XXI. 1 ed. São Paulo - SP: Oficina de textos, 2011. 328 p.

TUNDISI, José Galizia; BRAGA, Benedito; REBOUÇAS, Aldo. Os recursos hídricos e o futuro: síntese. In: REBOUÇAS, Aldo da Cunha (Org.); et al. Águas Doces no Brasil. 3. ed. São Paulo: Escrituras, 2006.

PARRON, Lucilia Maria; MUNIZ, Daphne Heloisa de Freitas; PEREIRA, Claudia Mara - Manual de procedimentos de amostragem e análise físico-química de água - EMBRAPA FLORESTAS, Colombo, Paraná, 2011. Disponivel em < http://www.infoteca.cnptia.embrapa.br/bitstream/doc/921050/1/Doc232ultimaversao.pdf> acesso em: 20 de jul. de 2014. 